\title{
$X X$. Extract from the account of the proceedings of the society of arts, sciences, and belles lettres, of bourdeaux, for the year 1805
}

\section{Messr. Leupold \& Messr. Dutrouilh}

To cite this article: Messr. Leupold \& Messr. Dutrouilh (1807) XX. Extract from the account of the proceedings of the society of arts, sciences, and belles lettres, of bourdeaux, for the year 1805, Philosophical Magazine Series 1, 27:106, 121-124, DOI: $10.1080 / 14786440708563567$

To link to this article: http://dx.doi.org/10.1080/14786440708563567

曲 Published online: 18 May 2009.

Submit your article to this journal $[\pi$

Џ Article views: 2

Q View related articles $₫$ 
electrified vapour; the latter being so held by caloric only might be called calorified vapour-in speaking of the difference between clouds properly so called, and those exhalations which return to the earth in the form of dew.

It will follow as a consequence from what has been advanced, that when a cloud by any means loses its electricity in an atmosphere below the freezing point, then snow will be produced; for the vapours will be frozen in the act of uniting : and for a similar reason it will follow, that particles of moisture united into rain, and passing through a cold region in their descent to the earth, will come down in the form of hail.

The influence which I ascribe to electricity in the production of all the phænomena before recited, agrees also perfectly with the well known fact, that rains are more abundant and frequent in mountainous than in flat countries. Indeed, if the remarks $I$ have presumed to offer are correct, this becomes so self-evident that more need not be added on the subject.

XX. Extract from the Account of the Proceedings of the Society of Arts, Sciences, and Belles Lettres, of Bourdeaux, for the Year 1805. Draun up by Messrs. LEUpocd and Durrouilh, Secretaries*.

M. Ducom has given the society a new method of determining the latitude at sea by two altitudes: it is founded upon this, that the time which we deduce from an observation made at the moment the sun passes by the prime vertical is exact, whatever may be the error which affects the latitude by account, which is requisite to be used in most of the methods now followed + . By this first observation, and the exact time which we deduce from it, we regulate the watch; and at any other time of the day a new altitude, with this exact time being known by the preceding operation, will give the true latitude.

* Extracted from Millin's Magazin Encyclopédique forMarch 1806, p. 150.

+ This idea is contained in a memoir of $M$. le Marquis de Verdun, printed at Brest. 


\section{Proceedings of the Society of Arts, Sciences, \&OC.}

The commissioners charged by the society with the examination of this method proposed by M. Ducom (Messrs. Lescan, Thibaut, and Leupold,) have compared it with those most practised at sea, and particularly with Douves's method. This last has been discussed at great length in a memuir by M. Mendoza, inserted in the Connoissance des Temps for 1793 ; but the author of this memoir only employs the differential formulæ in the discussion of the errors which might affect the elements of the calculation, which formula always suppose the errors to be extremely small. Much care and attention in making the observations, and a sufficient knowledge of the instruments made use of, reduce the errors in the altitudes, in the interval marked by the watch and in the declination, so as to be effectually very small : but it is not the same with errors which affect the latitude by account, which in certain circumstances may be considerable. As to the useful researches of M. Mendoza in his memoir, and to which we must refer in the cases before cited, the commissioners have added the examination of the influence which a considerable error in latitude might occasion.

They have given in their report a formula which expresses the error of the result given by Douves's method, in powers of the error which affects the latitude by account. In using this formula it will be necessary to take so many more terms of the series, according as the error in latitude is greater.

Among other consequences which this formula presents, it shows that Douves's method will always give an error which will be in a contrary sense to that which affects the latitude by account, and that this error increases rapidly as the latitude of the place of observation is greater, since the successive powers of the tangent of the latitude enter into his method.

It appears from the reports made by the above gentlemen that the method proposed by M. Ducom will give the latitude very exactly, whatever may be the error in the latitude by account, when, as the method requires, one of the two altitudes shall have been taken exactly at the passage by the prime vertical, or very near it.

This method has one inconvenience, that it is not always practicable: 
practicable: it cannot be done when the latitude and declination are of a contrary denomination; neither can it about the equinoxes, because the sun passes the prime vertical then in the horizon, or very near it.

The time when the second altitude is taken, which the anthor of the meinoir leaves to the observer's pleasure, has not appeared indifferent to the commissioners with regard to the greater accuracy of the result : they have engaged to turn their attention to the examination of the most favourable time for taking the second altitude *.

When circumstances will permit the proposed methud to be practised, it will be preferable to that of Douves, which, according to the formula given in the report, for an error at all considerable in the latitude by account, gives a result strongly erroneous.

M. Leupold has been occupied in a memnir, which he read to the society, upon the generation of urfuces of the second order. All of them may result from one common generation, which is executed by a curve of the second kind, variable in its dimensions, moved in such a manner that its plane may always remain parallel to itself. The equations which point out this circumstance give the law of the motion of the generatrix. This curve will be an ellipsis for surfaces having a centre, and a parabola for surfaces having no entre. In the case where each of the points of the generating curve has a right line for its direction, the surface may be engendered by a straight line moved in space. The analytical condition for this to happen indicates the hyperboloid with only one nappe, the hyperbolic paraboloid, and the parabolic cylinder. The common generatrix to all these surfaces may become a circle, except with regard to the hyperbolic paraboloid and the parabolic cylinder, for which the analysis used in this memoir shows that the generatrix can never be a circular curve.

This memoir is terminated by some general considerations upon the relation between elimination and the genera-

* In a note $M$. Ducom establishes, that the most favoutable time to take the second altitude is when the sun is near the meridian : he is occupied in determining the minimum of the interval between the two observations. 
tion of surfaces, and by an essay upon the general equation for surfaces of different orders which may be engendered by a right line.

XXI. On the Mineral Waters of Lipetzk, in the Province of Tambow, in Russia*.

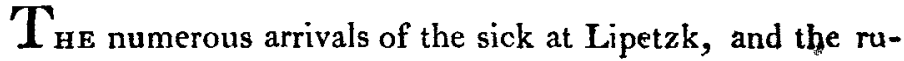
mours concerning the efficacy of its mineral waters, at last induced the Russian government to have their medical properties ascertained by chemical experiments and analysis.

The waters of Lipetzk were known in the reign of Peter the Great. This monarcb, while inspecting the manufactories of that town, was the first who took notice of their healing nature; they were however, upon the decline of the manufactures, neglected, and not in any repute till within the last three years. Invalids resort to them from all parts of the empire, and the arrivals during the last year (1803) were extremely numerous.

The town and the fountains are pleasantly situated. In consequence of the general abundance of provisions in the province of Tambow all the necessaries of life are extremely cheap; and the only difficulty that occurs, is to find lodgings and a suitable accommodation.

According to the analysis made by a gentleman of the faculty, Mr. Skell, commissioned for that purpose by the college, one pound of the mineral water of Lipetzk contains :

Carbonate of iron (ferrum carbonicum) - $\frac{20}{1} \frac{0}{6}$ grains.

Carbonate of lime (terra calcarea carbonica) $\frac{24}{20}$

Muriate of magnesia (magnesia muriatica) $\frac{16}{50}$

Sulphate of lime (calx sulphurica) - $\frac{6}{48}$.

Sulphate of soda (soda sulphurica) - $\frac{46}{T^{4} 6}$

Muriate of soda (soda muriatica) - $\frac{\frac{2}{2} \frac{1}{0} \frac{5}{6}}{2}$

Bitumen - $\quad-\quad$ - $\quad-\frac{7}{T_{0}^{7}}$

The uncertainty whether this water contains any gases, and what they are, induced the minister of the interior to

* From the Jotrnal of St. Petersinorg for the year 1804. 